\title{
Language and anxiety: an ethnographic study of international postgraduate students
}

\section{Lorraine Brown}

School of Services Management

University of Bournemouth

Dorset House

Talbot Campus

Poole

BH12 5BB

Email: Lbrown@bournemouth.ac.uk

\begin{abstract}
This paper presents some findings from an ethnographic study of international postgraduate students at a university in the South of England, which involved interviews and participant observation over a twelve-month academic year. One of the major themes that emerged from this research was students' anxiety over their level of English language. Although all students entered their course with a minimum level of IELTS 6, the majority felt disadvantaged by particularly poor spoken English, and suffered feelings of anxiety, shame and inferiority. Low self-confidence meant that they felt illequipped to engage in class discussion and in social interaction which used English as the medium of communication. A common reaction to stress caused by language problems was to retreat into monoethnic communication with students from the same country, further inhibiting progress in language. Whilst some linguistic progress was made by nearly all students during the academic sojourn, the anxiety suffered by students in the initial stage must not be underestimated, and appropriate support systems must be put in place to alleviate their distress.
\end{abstract}

\section{Key words:}

International students Higher Education Language

Anxiety Progress $\quad$ Support

\section{Author profile}


Lorraine Brown works in the School of Services Management at Bournemouth University as Programme Leader for the Tourism Masters Framework, and as study support lecturer for international postgraduate students. She is undertaking a PHD on the adaptation experience of international students to life in the UK. Her research interests include cross-cultural interaction, academic cultural dissonance, and conflicts in role and identity of the international sojourner. She belongs to the newlyestablished Culture Research Group at Bournemouth University.

\section{Introduction}

Since 1997, the number of international ${ }^{1}$ students studying in the UK has soared (Pelletier 2004; Taylor 2005), and is continuing to grow, with a specific $67 \%$ and $31 \%$ increase in the number of Chinese and Indian students respectively (UKCOSA 2006). Nationally, non-UK students make up 16\% of the total student population, with the percentage varying across institutions. Following the London School of Economics (LSE), which records the highest proportion of international students (at 62\%), the top five recruiting universities at which international students make up 25\% of the total student population are The University of Warwick, The School of Oriental and African Studies (SOAS), The University College London, The University of Surrey, and The Imperial College of Science, Technology \& Medicine (UKCOSA 2006).

There is a clear relationship between income generation and overseas recruitment in Higher Education (Pelletier 2004; Ryan and Carroll 2005a), as income from international students represents almost a third of the total fees income for universities and higher education colleges in the UK, with £4bn earned in fees and as much again in spending on living costs in the UK in 2004 (MacLeod 2006). In 2006, this figure grew to £5bn (ibid). Increasing overseas recruitment is the target of most universities (Ryan and Carroll 2005a), and in the UK, this has been encouraged by the Prime Minister's Initiative 2006, which urged British universities to extend recruitment to 100,000 more international students by 2011.

\footnotetext{
${ }^{1}$ Defined as any non-UK resident (Pelletier 2004).
} 
Accompanying the steady rise in the number of international students in global HE over the last twenty years has been a growth in the research dedicated to the international sojourn ${ }^{2}$, with adaptation being one of several interests (Pelletier 2004). Given the economic dependence of British universities on the fees from international students, it is important that there is a clear understanding of the issues facing students if an optimum service is to be delivered (Eland 2001; Ryan 2005; Smith 2006). This is seen by many writers (e.g. Ackers 1997; Lord and Dawson 2002) as not only the moral duty of universities seeking to attract full-paying students, but it will also result in improved student retention, positive word of mouth and therefore more successful recruitment (Allen and Higgins 1994; Smith 2006).

The move to a new environment is cited as one of the most traumatic events in a person's life as in most sojourners some degree of culture shock is inevitable (Hamburg and Adams 1967; Coelho 1974; Hamburg et al. 1974; Kim 1988; Berry 1994). Culture shock is defined as anxiety that results from losing the familiar signs and symbols of social intercourse, and their substitution by other cues that are strange (Hall 1959; Oberg 1960). Culture shock is a debilitating experience for many, and whilst an institution cannot completely offset all associated symptoms (Torbiorn 1994), awareness of the painful journey made by international students will inform the treatment offered by the range of staff who come into contact with students (Louie 2005; Ryan 2005).

Though a lot of research has been conducted on the strains and problems of transition to a new culture, a common criticism is that much is quantitative, descriptive, superficial and retrospective (Church 1982; Ward and Kennedy 1996; Pelletier 2004). Furthermore, most research has been conducted by international students themselves, as part of postgraduate study, and there is a paucity of research into the international student experience in the UK (Pelletier 2004). Many researchers (e.g. Taylor 1994; Potter 1996; Brewer 2000; O’Reilly 2005) recommend a longitudinal field study, with data collected at various points in time, to capture the adaptation process, and the use of a qualitative approach so that the inner world of the sojourner is captured.

\footnotetext{
${ }^{2}$ The term sojourn is used by Ward et al. (2001) to refer to temporary between-society culture contact.
} 
The study from which this paper's findings are taken fills the gap in the literature in respect of the methodological approach used, in that a year-long, ethnographic study of a mixed-nationality group of postgraduate international students was conducted, involving in-depth individual interviews with 13 students and overt observation of a postgraduate student body of almost 150 international students. Students were interviewed regularly, and observation took place on a daily basis to avoid producing a retrospective account of adaptation which involves subtle changes over time that are barely perceptible to the individual concerned, and may not be remembered accurately in hindsight (Brewer 2000;

O’Reilly 2005). Reflecting the increasing importance attached by feminist and qualitative researchers to the inner world of informants (Brewer 2000; Warren and Hackney 2000; Mason 2002), this study also differentiates itself by its focus on the emotional life of students. Indeed, the quest to understand the emotional journey undertaken by international students during their academic sojourn is what motivated this research. An inductive approach was chosen so that the themes that emerged from the analysis of data reflected the student view of adaptation rather than an outsider's imposed framework.

This paper will report on one of the major themes that emerged from this ethnographic study, that is the high incidence of anxiety in international students related to linguistic competence. Though all students in the postgraduate sample held IELTS 6, which tends to be the minimum entry qualification for most British universities (Macrae 1997), linguistic ability varied widely in the cohort, and in any case, IELTS is not an accurate reflection of language ability in the academic environment (Carroll 2005a).

A commonly-cited feature of culture shock is language shock caused by immersion into an environment where the dominant language spoken is not the sojourner’s native language (Storti 1990). Anxiety over language use is magnified for international students who face the challenge of operating in a foreign language, and achieving functional fitness in the academic and social setting very quickly (Persuad 1993; Cammish 1997; Carroll 2005a). Problems experienced by non-native speakers of English include: insufficient comprehension of lectures, seminar discussion and day-to-day conversation; limited fluency, grasp of grammar and vocabulary, serving to inhibit conversation and participation in class; and poor reading and writing skills. Commonly linked with such linguistic obstacles are the emotional reactions of embarrassment, impotence, shame, anxiety and frustration (Kim 1988; Kramsch 1993; Ward 2001): this is a function of being a non-native speaker in the early 
stage of the stay, when sojourners are preoccupied with making themselves understood (Ballard and Clanchy 1997). In reaction to stressful communication episodes, international students typically pursue an avoidance strategy of limiting or refusing participation in class (Okorocha 1996; Ballard and Clanchy 1997; Louie 2005). Listening and speaking are key language skills (Cammish 1997), but as shame over linguistic deficiencies and a fear of loss of face are common feelings among international students (Ryan 2005a), a strategy of passive observation in class is typical of the initial stage of the sojourn, until some linguistic competence is reached (Liu 2001). Furthermore, a segregation approach to interaction is widely observed among newly-arrived sojourners as communication with fellow nationals promises a relief from stress as well as a comforting reminder of home (Kim 1988; Storti 1990; Ward et al. 2001).

As Kim (1988) points out, however, the route to improving linguistic ability is by enduring the 'emotional lows' associated with foreign language use in order to gain communicative competence. Students who make the most progress are those whose friendship groups extend beyond the monoethnic ghetto; personality attributes such as extroversion and motivation are important in the choice of interaction strategy (Ward and Chang 1997; Gudykunst 1998). Improvements in language ability are also promised though contact with the host community, the most effective source of both culture and language learning (Gudykunst 1998). Unfortunately, such contact is rarely made, a source of disappointment for many international students (Ward 2001). International students are commonly willing to dedicate a huge amount of time to their study (Barker et al. 1991), which frequently calls for passive language learning skills such as reading. However, cross-national interaction and host contact are less widely practised, given students' desire to avoid stress-inducing communication attempts (Kim 1988).

In addition to the efforts made by students to improve their language skills, the receiving institution can do much to support its international student body by offering insessional and pre-sessional language support and by training its academic staff in awareness of the difficulties their students will face. As international student recruitment is primarily a way of increasing revenue at a time when government funding of Higher Education is being reduced (Ryan and Carroll 2005a), institutions are increasingly 
aware of the importance of student retention and progression in continued positive word-of-mouth marketing and are being forced to consider their support structures.

The aim of this paper is to use the insider perspective on the cultivation of linguistic competence as a sensitizing tool with which to the reflect on both the minimum English language requirements set by British universities, and the support structures offered to students, which are increasingly taken into account in choice of institution (Taylor 2005; Smith 2006).

\section{Methodology}

The aim of this study was to obtain the emic perspective on the adaptation process, an aim best fulfilled by the ethnographic approach which offered the opportunity to study students in the natural setting over a long period using the twin methods of participant observation and in-depth interviews (Fetterman 1998). Ethnographers mostly use purposive sampling, selecting a specific location and students (Daymon and Holloway 2002). The setting chosen for this research was the Graduate School at a university in the south of England, as I work there as a lecturer in English for Academic Purposes (EAP), and am already 'in the field'; I had direct access to students and ample opportunity for observation in an overt participant role. There were almost 150 postgraduate international students in the School from a range of nationalities. The majority of the students were from South East Asia, reflecting the most common source of international students for UK universities (UKCOSA 2006); around a third were from Europe, Africa and the Middle East.

Ethical approval to undertake this study was sought from the university Research Ethics Committee, and access to students was formally granted by the main gatekeeper, in this case, the Head of School. During induction week (in September), when I met the entire student group in my capacity as EAP lecturer, I introduced my research topic verbally and in writing, and asked for informed consent to observe and record observations on a daily basis. I also asked for volunteers for the interviewing aspect of the research. As students came forward, an information sheet was issued and students were reminded of confidentiality issues, their right to withdraw from the study, and the anonymity of data. 
As many students volunteered for the interview project, it transpired that interviewees were fairly representative of the population of 150 students with regard to nationality ${ }^{3}$, gender, age, living situation, religion and culture. Thirteen students were interviewed over a 12 month academic year (involving four pre-arranged, tape-recorded interviews lasting around 90 minutes each and many informal conversations). As is typical of ethnography, the first interview with students was informal and unstructured, and as advised by Spradley (1979), grand tour questions were used to stimulate conversation. Subsequent interviews were guided by the topics that had emerged in previous interviews, though I, the researcher, remained open to new topics that students wanted to raise, and indeed, new themes emerged throughout the academic year.

In addition to interviewing, participant observation was conducted throughout the year, so that the experience of the whole cohort of 150 students was taken into account, as an attempt at validity through the triangulation of methods (Brewer 2000). A further advantage is that I had access to interviewees outside the interview slots, so that events of significance could be captured throughout the sojourn and not just at prearranged points. As the term implies, being a participant observer involves not only watching a scene but also participating in it and recording events and conversations as they occur (Hammersley and Atkinson 1995). Examples of observation sites and occasions included: the classroom, the corridor, the library, the coffee bar, the canteen, the office, induction, social events organised by the School or University and by students themselves. The advantage of using my existing role as EAP tutor to facilitate research meant that my presence was not obtrusive to students (Mason 2002). Nevertheless, I found that I made notes on peculiarities that struck me (Hammersley and Atkinson 1995) in private or surreptitiously: although I was an overt observer, I felt that I would inhibit students if I took notes in their presence. As the field research progressed, data collection became focused for evidence (Schatzman and Strauss 1973), but at the beginning of this inductive research, all incidents and conversations were deemed to be relevant, and were recorded (time permitting) in a field journal on a daily basis. These field notes proved to be a rich source of data, with topics arising in

\footnotetext{
${ }^{3}$ The breakdown of the interviewees' nationality is as follows: Thai, Indonesian, Chinese, Taiwanese, Brazilian, South African, Malaysian, Slovenian, Russian, Jordanian, Iranian, Korean, and German.
} 
class, in tutorials etc, which also arose during the interviews, e.g. food, the weather, religion, drinking, language and study difficulties ${ }^{4}$.

The decision to study an institution at a particular time is significant (Ball 1983): I conducted the first round of interviews in the first week of term in 2003, being aware that students would have particularly intense emotional experiences at the start of term when they would be attempting to adapt not only to a new sociocultural environment but also to a probably unfamiliar academic situation. Similarly, observation started on the first day of induction in September 2003 and finished two weeks after dissertation submission. Subsequent interviews were held at three monthly intervals, in an attempt to avoid a retrospective account of the sojourn. The second round of interviews was conducted just after the Christmas holiday. I conducted the third round of interviews shortly after the Easter holiday, towards the end of the taught part of the course (six-months). I ended the ethnographic data collection at the end of the academic year, in September 2004, upon student dissertation submission, which meant that I captured the total academic experience for a Masters student.

After the first interviews had been conducted in the first weeks of term (October 2003) and observation had begun, preliminary analysis, involving coding field and interview data, was carried out. Coding meant reading through notes and repeatedly listening to tapes and reading transcripts until themes or categories (an example of which is language anxiety) began to emerge, as certain phrases events, activities, ideas etc occurred repeatedly in the text. I undertook four rounds of 13 interviews, and after each round, the transcript was scrutinised, and recurring topics were highlighted to be followed up in the next interview. Once the interview transcripts were analysed, I searched through the field notes and email correspondence for anything the student had said during class etc, to feed into the subsequent interview. To facilitate the process, I created a codebook, with a list of codes after analysing the first round of interviews, which I updated as the data collection proceeded. As in much qualitative research, an inductive approach was adopted; therefore the literature on the key themes was reviewed after the final round of interviews was conducted.

\footnotetext{
${ }^{4}$ A distinction is made between interviewees and students in this paper, the latter referring to findings from the observation aspect of the study.
} 


\section{Data analysis}

\subsection{The shock of arrival}

Given recognition of the need for a high level of English, to meet the demands of the course and to cope in an English-speaking environment, nearly all of the interviewees described taking an intensive course in English before they arrived, in addition to obtaining IELTS 6; nevertheless, in the first interview and in the first few months, language was a major preoccupation, especially in terms of meeting the demands of an intensive assignment-driven programme. Many interviewees described the shock of arrival in the UK, and confrontation with spoken English in everyday life, some days before the academic task began, which exacerbated their discomfort over being in a new culture as well as their homesickness, as previous studies show (Storti 1990; Persaud 1993; Ballard and Clanchy 1997). Interviewees spoke of the panic induced when having to speak in English with people at the airport, the coach and train station, with taxi drivers, shop assistants, with university library staff and their course administrators, owing to poor listening and speaking skills. This sense of panic is reflected in the following exclamation by the Jordanian interviewee:

Oh my God, everything is in English, and I don't know what it all means!!

Anxiety was experienced over approaching local people in any social context, such as asking for directions or for prices in shops, because of a fear of making mistakes in spoken English, and of irritating people if they needed to repeat or rephrase what they had said, as shown in the comment by the Iranian interviewee that

Just I try to hide away someplace because I don't want to annoy.

Frustration was a frequently mentioned sensation by interviewees if they could not make themselves understood, as described by the Indonesian interviewee:

Sometimes it's annoying when you say something and they don't get it!

Frustration is a common reaction to such communication breakdown, according to Kim (1988), a function of being a non-native speaker in the early stage of the stay. Many interviewees felt dissatisfied with their communication attempts which often led to the common outcome of message abandonment 
or topic avoidance, whereby speakers begin to talk and stop mid-sentence, or avoid a difficult topic altogether (Tarone and Yule 1987). In the extreme, some interviewees said that they avoided contact with local people altogether, getting friends to speak for them, in a bid to avoid the inevitable feelings of frustration and stress associated with communication in a foreign language (Kim 1988; Ward et al. 2001). However, speaking in English could not be avoided altogether: as Gudykunst (1983) notes, students have to adapt at least minimally to the new environment, therefore some stress was inevitable for all students.

Many interviewees confessed to a sense of helplessness and ineptitude in the first few weeks arising from an almost daily occurrence of communication breakdown, as reflected in the following cry by the Iranian interviewee:

Because you can't speak English, you don't know people, you don't know a thing, it's really difficult. According to Kramsch (1993), a feeling of impotence is commonplace in the initial stage of the sojourn, as the visitor feels they revert to the mental state of an infant in which they have to learn to do simple things again, reflected in the above interviewee's description of herself of as a little girl when speaking in English.

Many interviewees were burdened by feelings of shame and inadequacy over their low level English, as described by the Thai interviewee: You know you be embarrassed when you can't speak English. Embarrassment over language ability was widespread among all students, witnessed in shy smiles, blushing and avoidance of eye contact during conversations and class discussion. Furthermore, among many interviewees, and particularly in the case of the Korean interviewee, accounts of attempts to cope linguistically were accompanied by facial gestures such as wincing and frowning, as well as nervous laughter. The widespread feeling of inadequacy was compounded by a clash in differences between status at home and abroad: an uncomfortable position of inferiority in relation to language (Brumfit 1993; Kramsch 1993) was unfamiliar to interviewees whose careers at home included lecturer, translator and government official. A fear of making mistakes and thereby worsening their feeling of inadequacy led to a strategy of avoiding host contact or speaking in English, until confidence improved, but, according to Kim (1988), linguistic competence grows in line with exposure to the host language, which necessarily involves suffering emotional lows and dips in well-being, until 
competence is achieved. Given the negative feelings associated by many with speaking in English, it was no wonder that many interviewees described feeling sad about their inadequate language skills, and felt a longing to hear and speak their native language (see Garza-Guerro 1974; Giddens 1991; Ryan 2005) as well as being tired due to the effort needed to sustain conversations in a foreign language and to cope with the accompanying anxiety.

The level of anxiety surrounding language ability was intense in the first few months of the semester, reflected in the amount of time dedicated to the topic in interview 1 and the reference made by almost all interviewees to nerves over language level in the build-up to departure from the home country. This preoccupation extended to almost all students in the cohort as tensions ran high over their ability to cope with assignments and lectures, as reflected in the following common refrain:

I am so frightened about my English ～(Korean student, October 7)

As any study support tutor will recognise, in the first month I was inundated with email messages and visits to my office from students who were often in tears of panic over their ability to cope linguistically with the demands of the course. The following request to talk to me about problems with listening comprehension in lectures is typical:

Taiwanese student came to see me to discuss her inability to follow the lecturer, wanted to know what she should do. This begs the question - should she be on a Masters course if her English is so poor? October 21

Whilst it is true that writing and reading skills are vital for academic success (Cammish 1997; Carroll 2005b), and though students experienced difficulties in these areas, the concern of most students was over oral ability, as most distress was caused by an inability to communicate with confidence and ease in face-to-face encounters, which required immediate feedback and response, and carried the potential for embarrassment The justification for anxiety over speaking skills was confirmed in my participation in and observation of everyday conversations, as students' speech was typically halting and stilted, caused by the search (as described by interviewees) to find the right vocabulary, and was accompanied by smiles of embarrassment and looks of panic, particularly if they could not understand a question or comment. Great patience was called upon when conversing with the majority of students, as very often I found that I had to repeat or rephrase questions and comments, taking care not to make them uncomfortable, and I also found that I had to try to interpret what students said, as they were not always 
(or often) clear. Sensitivity to problems in cross-cultural communication is not an unfamiliar skill to an EAP tutor, however all lecturers have a duty to monitor their language use and to check for students' comprehension (Cammish 1997; Carroll 2005a). Without the communication skills needed in speaking with non-native speakers, it was not hard for me to understand how contact with local people unused to adapting their communication patterns might be stressful: as Carroll (2005a) points out, successful communication with non-native speakers is facilitated through the adoption by native speakers of 'plain' English and the display of a patient empathetic attitude. Unfortunately, as this study found, local people may not be willing to make the effort to befriend international students if conversation is difficult (Ryan 2005).

In addition to problems with spoken language, confusion was exacerbated by a detection among interviewees of some differences in non-verbal communication, with particular mention of a difficulty in reading the expression of emotion and ascertaining the appropriate level of physical contact, with the fear that they may make intercultural mistakes that are so common in intercultural contact (Smith 1987; Brumfit 1993). For example, the Taiwanese and Chinese interviewees found it hard to detect when local people were annoyed, and worried that if they misread facial expressions, they could cause offence. Meanwhile, the Iranian interviewee was nervous of bumping into people on the street because in Iran, physical contact is to be avoided: I don't want to annoy them (English people). On the other hand, the Brazilian interviewee was aware that he was more tactile than most British people, and had to constantly remind himself that he was in a country with different rules of operating: physical contact varies across cultures, and needs to be modified according to the situation (Gudykunst 1998). Cammish (1997) argues that communicative competence goes beyond linguistic ability; unless people understand the subtle cues implicit in tone, gesture, and expression, they will misinterpret what is said and may cause offence. This view is shared by many writers (e.g. Smith 1987; Torbiorn 1994) who claim that non-verbal communication is just as if not more important than verbal language in cross-cultural communication. However, this study found that the main preoccupation of students throughout their stay was over linguistic ability and its improvement, confirming Hofstede’s claim (1991) that without linguistic competence, adjustment cannot be achieved. The findings from this research support the view of Scollon and Scollon (1995) that the claims made about the role of non-verbal communication in interethnic communication are exaggerated. Linguistic competence has to be developed before non- 
verbal communication can be mastered, otherwise any interaction with the host is avoided or minimised.

Lacking language facility can cause a dip in confidence and self-esteem in international students (Ryan 2005), as they struggle with day-to-day tasks and academic tasks (Carroll 2005): indeed in this study, anxiety did not diminish until students had achieved some proficiency in spoken English, taking longer to develop in some students than in others. For three out of 150 students, despair over poor language was cited as the reason for leaving the course and either returning home, or attending a local language school to improve speaking and listening skills.

\subsection{Practising spoken English}

Despite the stress of speaking in a foreign language (Kim 1988), host contact was recognised by all interviewees as a precondition for improvements in linguistic ability, as acknowledged by the Iranian interviewee:

Speaking still, I have lots of problems. If I had English friend, I'm sure it was better.

Meanwhile, the Indonesian interviewee attributed her progress by Interview 4 to her own determination to reach out to and speak with local people:

I'm thinking because I've been here for one year, my language has improved; I'm always talking in English. If I cannot understand, I ask the British, especially if they use slang words.

At the start of the sojourn, all interviewees made the promise to themselves that they would try to learn about British culture and to improve their English during their stay through the maximisation of contact with locals, who they saw as being fundamental to their learning. Host contact took the form of interaction with housemates, work mates and parents at children's schools. Given the overwhelmingly international make-up of the course (there were only three British students on the course), there was little chance for interaction with local students, to the regret of many. By Interview 2, it became clear that most students were enjoying only limited contact with the host, the best resource for language improvement (Ryan 2005); therefore most improvements in English were made through speaking 
English with other nationalities, which many saw as a very poor second best, according to some, marking a deterioration in spoken English.

Despite awareness that speaking in English was vital for improvements in speaking skills, such despair was felt by many students over their poor speaking skills, particularly if they compared themselves to better speaking students (comparisons were often made by Asian students with better speaking European students) that many withdrew from the cross-cultural setting. In order to avoid committing mistakes which are inevitable and universal in the early stage of the sojourn (Kim 1988), the majority of the student cohort, as observed in and outside the academic situation, and as discussed in interviews, interacted extensively and almost exclusively with their compatriots. When citing the reasons for speaking in the native language, the words most commonly used referred to feelings of belonging, relaxation and comfort. Interviewees repeatedly used words such as cosy, comfortable and nice to describe their feelings about speaking in their own language. According to Kim (1988), the most intrinsic and lasting function of ethnic social communication, is the sense of connection with 'home', an advantage of speaking in the native language mentioned by many interviewees. This feeling is defined by Bauman (1999) as being in a space where one 'seldom, if at all, finds oneself at a loss, feels lost for words or uncertain how to act” (P. xxiii), which contrasts with the distress of speaking in a foreign language. By speaking the native language, interviewees could avoid what Bauman (1999) refers to as 'out there', a place which is associated with incoherence and helplessness, with the stressful experiences involved in speaking in English. On a more mundane level, socialisation in national groups was also sought by interviewees to avoid the fatigue imposed by speaking in a foreign language for long periods, in other words to aid relaxation, as found in other studies (e.g. Lewins 1990; Ryan 2005).

On the other hand, students wanted to improve their English, which they knew they could achieve only through speaking in English, a catch-22 represented by the Korean interviewee:

I need to speak English. But my English is not so good, I think so always I feel difficulties in talking about the native speakers and I want to improve my English but I'm so shy. 
Interviewees therefore recognised that speaking their own language too often was detrimental to their progress in English (Kim 1988; Ryan 2005), as commented on by the Thai interviewee: It's getting worse because I speak Thai all the time, every day I meet all the Thais, it's a big group. Furthermore, a positive attitude towards conational friends who are sought for their emotional support is associated with a decrease in socialising with other nationalities (Furnham and Erdmann 1995), as this study found, as those who gravitated towards their national in-group mixed less with other nationalities. Indeed, it became clear that those who mixed across national groups saw a greater improvement in their spoken English, as well as in their cultural knowledge. The Jordanian interviewee, for example was the only Jordanian on the course, and acknowledged that although he missed not speaking in Arabic and receiving help from conational friends, If I always speak in my own language, my vocabulary would be maybe the same or lower. Maybe the Arabic students would help me if I missed a lecture, but maybe my English would be the same, so what's the point?

All students were aware that operating in English was vital for their linguistic progress, but could neither give up the comfort and identification associated with speaking their mother tongue, nor endure the anxiety associated with communication in what they perceived as poor spoken English. Over the course of the year, the patterns of language spoken within the first few months were maintained, with the Asian students mixing in co-national groups and speaking their own language.

\subsection{Speaking in class}

Whilst students could minimise the amount of English spoken in their social life, they could not avoid the challenge of speaking in the class room situation. During the first semester, the low level of participation in discussion among particularly South East Asian students (who made up the majority of the cohort) was noted in observation of my own EAP sessions and in conversations with other lecturers. As Ballard and Clanchy (1997) state, at first lectures and tutorials can send many international students into learning shock; they will sit silently, rarely volunteering an answer unless picked on. In my classes, not only did the majority (if not all) South East Asian students avoid answering questions, but they also avoided eye contact, so that until names were mastered, it was challenging to elicit a response from them. When students became aware that a response was expected, 
the looks that crossed their face included panic and anxiety, and in extreme cases, students sat silently, squirming in their seat. This had the effect that I felt uncomfortable about subjecting them to feelings of anxiety, and yet I knew that speaking in class was a skill that they needed to acquire and use in the rest of the programme; therefore I adopted the following strategy where I could:

As I am aware that many students are embarrassed about speaking publicly - shown in quiet voices that others struggle to hear and immediately going red as I call upon them to speak - I make sure that I know they will know the answer to the question before I pick on them. Even then though their answers are very hesitant, and there is always a rueful smile. October 21 Despite acknowledgement that I am as trapped in my own educational upbringing as international students are in theirs (Hofstede 1991; Ballard and Clanchy 1997; Louie 2005), transfer to a teachercentred culture, with which the majority of students were comfortable was not an option: whilst I understood the influence of students' socialisation in their previous educational culture (Carroll 2005b), my job was to help them to adapt to the norms of the new educational system, which differed in many ways from their own, as a function of differences in the cultural dimensions of Power Distance and Uncertainty Avoidance (Hofstede 1991). As Chan and Drover (1997) argue, educational culture is an extension of national culture, and like any other aspect of culture, it is deeply ingrained and at the level of unconscious thought until immersion in an alien setting (Hall 1959) brings about a need for change and reflection on unconscious values. As Herskovits (1973), states, the educational process is a means for transmitting various aspects of culture, and the EAP class represented for students a gentler companion to the mass lecture format of the rest of the Programme and a less intimidating atmosphere for the practice of seminar participation.

As they had no idea what the lecturer's strategy would be for eliciting contributions, interviewees described suffering apprehension throughout the majority of lectures in the first semester. Interviewees attributed their lack of participation as a result of poor English, a connection made by all students, either in observation of themselves or others. As described by a Taiwanese student in a tutorial, many students were inhibited by the slowness of their listening comprehension:

C. feels she only understands half. She spends so long translating words into her language that when she returns to the lecture she has missed another 9 sentences, so there is not time to think about what she would like to say $\quad$ October 28 
Until listening skills could be improved, students described not daring to answer a question. On occasions when questions were directed at them, interviewees described feeling panic in case they misunderstood and gave the wrong answer, as often happened. As Cammish (1997) points out, listening is a complicated process, a receptive skill involving the listener in receiving, decoding, understanding and reacting to messages. Even when a question was understood, interviewees stated that they then experienced panic over the need to respond quickly, and as articulately as possible, something which is difficult in a foreign language (Okorocha 1996; Carroll 2005a). Comparisons with more linguistically able class mates were common, and further deterred students from participating, as interviewees described wanting to avoid the feeling of inferiority they suffered if they made more mistakes than others, as commented on by the Chinese interviewee in interview 2:

I think writing and listening are ok, but I still not satisfied with my spoken English, it's full of mistakes. That embarrasses me.

Similarly, in interview 2, the Korean interviewee said that she wished she could participate, she had many ideas, but I have to remain silent. During the time that she spoke about her feelings of linguistic inadequacy, she screwed up her face and winced in displeasure with herself. The fear of loss of face is common (Barker 1997; Ryan 2005), as is the strategy of withdrawal from the communicative arena and passive observation until some competence is reached (Liu 2001), a strategy adopted by students in both academic and social life.

This suggests then that participation should grow as linguistic competence develops; indeed, it took many weeks before small changes were noted in students’ participation in my classes, even though many interviewees commented that it was easier to speak in this smaller forum, because they said that I tended to speak more clearly and seemed better able to understand what they were trying to say when they lost their way. This observation would imply support for the case for training for academic staff to improve their delivery, and at least for attention by lecturers to the comprehension of students (Carroll 2005b).

That language ability influences the desire and ability of students to contribute to class discussion is clear in this study. However, the debate in the literature over what impacts on students the most, cultural background or linguistic ability (e.g. Furneaux et al. 1991; Ballard and Clanchy 1997; McLean 
and Ransom 2005) must be addressed. It was observed during the field research that Greek students participated extensively in class, despite, not because of, the level of their language prowess: their linguistic ability was quite low, and they made many mistakes in speaking, as pointed to enviously by the Chinese interviewee:

Even if their pronunciation is not perfect, I think they are braver to express themselves, and I am always thinking about any mistakes I will make.

On the other hand, many of the Asian students with a high level of spoken English, as witnessed in one-to-one conversations hesitated to speak in class, as reflected on by a Brazilian student:

They are so quiet, very reserved, but I don't know why they are so afraid of saying things, because, you know, they are very good. I've met so many people that were so quiet, but they were so intelligent. When you see something they've done you think, 'oh my god, you've got such brilliant ideas.' The overall lack of participation in class by South East Asian students meant that, particularly in the beginning of the sojourn, a passive, teacher-centred educational experience was often recreated, leading to frustration and irritation on the part of many students and lecturers alike. For some European students, the resulting feeling was embarrassment over a domination of discussion that they didn’t welcome:

After today's class, a German student told me that she feels very uncomfortable about how much she speaks compared to others: 'I am not a bully. I don't like this feeling'. October 21

The prevalence of non-participation among Asian students regardless in some cases of language ability, and the incidence of participation among poorly speaking students used to a culture of class participation confirms the contention that the university seminar constitutes a cultural as much as a linguistic challenge (Barker et al. 1991; Hofstede 1991; Persaud 1993), one which must be addressed by both students and staff to avoid the problematisation of the presence of international students (McLean and Ransom 2005). Notwithstanding the importance of cultural differences in class discussion, this study showed that without a growth in confidence in speaking and listening skills, many students did not find the necessary strength of character to overcome the cultural barriers: linguistic competence was a precondition for many students of participation.

\subsection{Progress in language}


Given my close involvement with students and interviewees, in my capacity as researcher and EAP tutor, it was possible for me to observe the linguistic progress of many students. During the course of the academic year, most students made steady progress in their spoken English, as observed in weekly EAP classes and tutorials, as well as in casual conversation. Progress was gauged by my speed of spoken English in conversations with students: as time passed, I found that I spoke more quickly with students, as I could detect improvements in their aural comprehension. This observation confirms the view that the onus is on staff to monitor students' comprehension, and to adapt their speed of delivery and vocabulary to the situation (Cammish 1997; Carroll 2005a). A contrast between conversations with students in the initial stage of the sojourn and those about to leave was facilitated by not only a review of interview transcripts, but also by an overlap between the arrival of the September 2004 cohort (who do not form part of this study) and the departure of this study's informants: there was a marked difference between the fluency and vocabulary of the cohort under study, and those newly arriving. By the third interview, the majority of interviewees had made progress in terms of improved vocabulary and grammatical accuracy, greater speed of delivery, intonation and pronunciation, and fewer hesitations between questions and answers. As an ethnographer, I am committed to incorporating the emic view of the sojourn (Fetterman 1998), thus it is important to note that interviewees themselves pointed to a difference between their language ability in the initial and later stages, as vividly commented on by the Indonesian interviewee:

In the beginning I felt my English was so horrible. If I had to talk with the British I felt very nervous, sometimes my grammar is not good. I say yesterday with the present tense. My English was ugh! Improved language facilitated communication owing to a decrease in the panic felt in the earlier months, as explained by the Taiwanese interviewee:

I think the more I live here, there is improvement. I mean maybe I can speak more quickly and for the listening it's easier for me. I'm not so scared.

Thus, the grasp of vocabulary and grammar was the first step in communication ability. Whilst linguistic ability does not mean there will be interaction with the host (Ward and Kennedy 1993; Torbiorn 1994), this was not the concern of students initially; what they wanted at first was to grasp communication in practical and face-to-face situations (Cammish 1997). 
The key change for many interviewees was an increase in confidence afforded by improved language skills, with the following comment by the Indonesian interviewee typifying students' feelings: all situations easy now.

Whereas previously the Iranian interviewee had equated deficiency in language with blindness, now she equated her progress with mobility, confirming the link between language ability and adjustment (Hofstede 1991): after two, three months you think when you put your leg on the ground you have confidence to walk! It took one year, but now almost I have no problem.

Progress varied among interviewees, with some students making much progress, and others much less, and with some interviewees, for example, the Thai and Korean interviewees still confessing to feelings of insecurity about their English. As Kramsch (1993) states, whilst feelings of inadequacy tend to subside as language ability grows they never completely disappear. There is a clear consensus in the literature that foreign language ability is negatively impacted by monoethnic communication (Kim 1988; Furnham and Erdmann 1995; Ryan 2005): this correlation is confirmed in this study, as those who mixed extensively with their conational students made less progress than those who did not.

Nevertheless, as Table 1 shows, my observation is that all students, regardless of friendship groups, made some progress: this is to be expected given that they had lived in England for one year; at least minimally they had to operate in English on a daily basis even if the foreign language was only used in mundane activities such as shopping. An increase in vocabulary was also inevitable given the amount of reading needed for the course.

Table 1: Interviewees’ linguistic progress

\begin{tabular}{|l|l|}
\hline \multicolumn{1}{|c|}{ Interviewee nationality } & Researcher's comment \\
\hline Jordanian & $\begin{array}{l}\text { Confidence grown, fast delivery. Says he can now } \\
\text { communicate in all situations. }\end{array}$ \\
\hline Taiwanese & More fluent, improved vocabulary. \\
\hline Chinese & $\begin{array}{l}\text { Excellent vocabulary and aural ability. Confesses } \\
\text { that she can communicate in all social situations. }\end{array}$ \\
\hline Thai & $\begin{array}{l}\text { Speaking more quickly now, but not confident. I } \\
\text { have to repeat and explain a lot. }\end{array}$ \\
\hline
\end{tabular}




\begin{tabular}{|l|l|}
\hline Russian & Improved vocabulary and speed \\
\hline Indonesian & $\begin{array}{l}\text { Speaking fluently and quickly. Says she’s } \\
\text { completely confident. }\end{array}$ \\
\hline Iranian & Speed and vocabulary much improved \\
\hline Slovenian, Brazilian and German & Fluent - even better than when they first arrived \\
\hline Korean & $\begin{array}{l}\text { Little confidence, improved speed and } \\
\text { vocabulary, but I have to repeat a lot. }\end{array}$ \\
\hline
\end{tabular}

However, language proficiency would certainly have been greater in interviewees if they had practised their spoken English more often and if they had reduced their interaction with conational students: this was a course of action barred by their perceived poor level of English.

\section{Discussion: Higher Education and minimum proficiency requirements}

As well as inducing anxiety in many international students, there was consensus among the few linguistically adept students in this study (including the Brazilian, German and Slovenian interviewees) that the level of the course was brought down by the linguistic incompetence of the majority of the cohort. This was a view shared by the three British students on the course who questioned the competence of their colleagues, and felt that the level of English accepted by British universities should be addressed. At present, the minimum entry qualification for most British universities is IELTS 6, although there is evidence to suggest that some institutions have no such requirement, the longer-term result of which is the creation of even more negative feeling than portrayed in the current study (Carroll 2005a). The IELTS test is not a consistently reliable indicator of language ability in the academic setting; however, the limitations of language testing are not likely to be resolved in the foreseeable future, given the difficulties involved in creating a test of academic and linguistic ability (ibid). Increasing the minimum language requirement to IELTS 7 may not guarantee improved language ability, and besides such a change in recruitment policy in a volatile and competitive market would only happen in an ideal world, we don't live in an ideal world (Brazilian interviewee). 
To address the incidence of anxiety in international students caused by an inability to communicate well in the first few months, the question then may be one of modification of support structures rather than increased language requirements. At the university at which this study was conducted, students suffered distress over their language ability even though they had access to weekly study support classes and tutorial support. However, no commitment was made to provide language support to weak students, who would benefit from an intensive language course at the beginning of the semester. Comparisons with other schools which provide no support at all show a high failure rate, and one would imagine, a greater level of distress among students. It should be considered that if we continue to recruit students whose language level we know may impede their adjustment and be counter to psychological health, institutions have the moral duty to put in place systems of support to facilitate the acquisition of language skills, starting in induction week (Ackers 1997; Lord and Dawson 2002). This is all the more important for postgraduate students who need to achieve functional fitness very quickly in the academic sojourn: it is important to observe that of 318000 students in British Higher Education, 106000 are postgraduates (UKCOSA 2006). However, support is sporadic and varies dramatically between and even within institutions. As the market for international students is increasingly competitive, HE institutions need to provide an optimum service for students who are increasingly assertive and aware of their consumer power (Taylor 2005; Smith 2006); otherwise their future recruitment will be endangered (UKCOSA 2004; Taylor 2005; Ryan 2005; NUS 2006).

Meanwhile, as Cammish (1997) points out, students need to make individual efforts to overcome linguistic problems, and as this study found, the majority of students impeded their own linguistic development by interacting mainly with conational students and speaking their native language, instead of speaking in English. According to Gudykunst and Nishida (2001), the skill of anxiety management is central to surviving and succeeding in the cross-cultural sojourn. For those students who withstood the anxiety associated with speaking in English, more progress in language was made than in those who retreated into monoethnic groups. Therefore, the motivation of the individual is an important variable in the acquisition of linguistic competence (Gudykunst 1998).

Finally, lecturing staff can do much to improve the student experience, by becoming explicit in their academic requirements and by paying attention to their own communication techniques (Todd 1997; 
Carroll 2005a; Carroll 2005b). Furthermore, staff should address the cultural component of their own behaviour and expectations to avoid the adoption of an ethnocentric attitude towards international students who are often problematised because they are different (McLean and Ransom 2005).

\section{Conclusion}

The findings from the ethnographic research reported in this paper are clear: many international students suffer anxiety owing to the stress of communicating and studying in a foreign language, and the level of language with which many enter university inhibits their successful academic and sociocultural adjustment. This paper points to a high level of anxiety among many international students in the initial stage of the academic sojourn with regard to language ability, with difficulties posed by an inability to communicate in day-to-day situations, to follow lectures, and to participate in class. The stress in interviews was placed overwhelmingly on linguistic competence, rather than on the mastery of non-verbal communicative competence. The emphasis in the literature on non-verbal communication is not reflected in this study, possibly because the aim of the sojourn was to achieve academic success, an emphasis confirmed by Blue (1993) and Sharples (1995).

It is to be expected then that students did not refer to themselves as being completely settled until the degree of linguistic competence was achieved, which would enable a minimum accommodation with academic tasks. This study confirms the contention that culture shock is a transitory state, as most students noted a decrease in anxiety related to language ability as time passed and as improvements were noted. There were variations in language progress, however, with most improvements noted in those students who avoided or minimised monoethnic contact and maximised their use of English in daily life, confirming the link in the literature between ethnic communication and deterioration in host language competence. Anxiety over language ability is an inevitable part of the experience of culture shock for non-native speakers, however, this study has shown that this is a debilitating feature of the academic sojourn, and there is much that the institution can do to help students survive the initial few months of their stay. 


\section{References}

Ackers, J. (1997) Evaluating UK courses: the perspective of the overseas student. In: McNamara, D. and Harris, R. Eds. Overseas students in HE: issues in teaching and learning. London: Routledge

Allen, A. and Higgins, T. (1994) Higher education: the international student experience HEIST in association with UCAS

Ball, S (1983) Case study research in education In: Hammersley, M. Ed. Educational research: current issues London, Chapman / Open University

Ballard, B. and Clanchy, J. (1997) Teaching international students. Deakin: IDP

Barker, M.; Child, C.; Gallois, C.; Jones, E.; Callan, V. ～(1991) Difficulties of overseas students in social and academic situations Australian Journal of Psychology, 43, 2, 79-84

Barker, J. (1997) The purpose of study, attitudes to study and staff-student relationships. In: McNamara, D. and Harris, R. Eds. Overseas students in HE: issues in teaching and learning. London: Routledge

Bauman, Z. (1999) Culture as praxis London, Sage

Berry, J. (1994) Acculturation and psychological adaptation: an overview In: Bouvy, A-M.; van de Vijver, F.; Boski, P. and Schmitz, P. Eds. Journeys into cross-cultural psychology Amsterdam, S\&Z

Blue, G. Ed. (1993) Language, learning and success: studying through English.

Vol. 3, $1 \quad$ London: Macmillan

Brewer, J. (2000) Ethnography Buckingham, OUP

Brumfit, C. (1993) Culture and success: a general model, and its applicability for EAP learners In: Blue, G. Ed. Language, learning and success: studying through English Vol. 3, 1 London, Macmillan

Cammish, N. (1997) Through a looking glass darkly: problems of studying at advanced level through the medium of English In McNamara, D. and Harris, R. Eds.Overseas students in HE: issues in teaching and learning London, Routledge

Carroll, J. (2005a) 'Lightening the load': teaching in English, learning in English In: Carroll, J. and Ryan, J. Teaching international students Abingdon: Routledge

Carroll, J. $\quad$ (2005b) Strategies for becoming more explicit

In: Carroll, J. and Ryan, J. Teaching international students Abingdon: Routledge

Chan, D. and Drover, G. (1997) Teaching and learning for overseas students: the Hong Kong connection. In: McNamara, D. and Harris, R. Eds. Overseas students in HE: issues in teaching and learning. London: Routledge

Church, A. (1982) Sojourner adjustment $\quad$ Psychological Bulletin, 91, 3, 540-572

Coelho, G.; Hamburg, D. and Adams, J., Eds. ～(1974) Coping and adaptation. New York: Basic Books 
Daymon, C. and Holloway, I. Marketing Communications.
(2002) Qualitative research methods in Public Relations and London: Routledge

Eland, A.J. (2001) Intersection of academics and culture: the academic experience of international graduate students University of Minnesota

Fetterman, D. (1998) Ethnography London: Sage

Furneaux, C.; Locke, C.; Robinson, P.; Tonkyn, A. (1991) Talking heads and shifting bottoms: the ethnography of academic seminars. In: Adams, P.; Heaton, B.; Howarth, A. Eds.

Socio-cultural issues in English for Academic Purposes.. $\quad$ Vol. 1, $2 \quad$ London: Macmillan

Furnham, A. and Erdmann, S. (1995) Psychological and sociocultural variables as predictors of adjustment in cross-cultural transitions Psychologia, 38, 238-251

Garza-Guerrero, A. (1974) Culture shock: its mourning and the vicissitudes of identity Journal of the American Psychoanalytic Association, 22, 408-429

Giddens, A. (1991) Modernity and self-identity: self and society in the late modern age. Cambridge: Blackwell

Gudykunst, W (1983) Toward a typology of stranger-host relationships. International Journal of Intercultural Relations, 7, 401-13

Gudykunst, W. (1998) Bridging differences: effective intergroup communication. London: Sage

Gudykunst, W. and Nishida, T. (2001) Anxiety, uncertainty, and perceived effectiveness of communication across relationships and cultures International Journal of Intercultural Relations, 25, 55-71

Hall, E. (1959) The silent language. N New York: Doubleday

Hamburg, D. and Adams, J.

(1967) A perspective on coping behaviour: seeking and utilising information in major transitions. Archives of General Psychiatry, 17, 277-284

Hammersley, M. and Atkinson, P. (1995) Ethnography Principles in practice. London: Tavistock Publications

Herskovits, M. (1973) Education and the sanction of customs In: Ianni, F. and Storey, E. Eds. Cultural relevance and educational issues Boston, LB

Hofstede, G. (1991) Cultures and organisation: software of the mind. London: HarperCollins

Kim, Y. (1988) Communication and cross-cultural adaptation. Clevedon: Multilingual Matters

Kramsch, C. (1993) Context and culture in language teaching Oxford, OUP

Lewins, H. (1990) Living needs In: Kinnell, M. Ed. The learning experiences of overseas students Buckingham, OUP/SRHE

Lord, P. and Dawson, C. (2002) The Induction needs of international students at postgraduate level. London: TVU

Louie, K. (2005) Gathering cultural knowledge: useful or use with care?

In: Carroll, J. and Ryan, J. Teaching international students Abingdon: Routledge 
Liu, M-C. (2001) The adaptation and experience of foreign-born faculty members in the US The Claremont Graduate University

MacLeod, D. (2006) International rescue The Guardian April 18,

Macrae, M. (1997) The induction of international students to academic life in the UK In: McNamara, D. and Harris, R. Eds. Overseas students in HE: issues in teaching and learning London , Routledge

Mason, J. (2002) Qualitative researching. London: Sage

McLean, P. and Ransom, L. (2005) Building intercultural competencies: implications for academic skills development In: Carroll, J. and Ryan, J. Teaching international students Abingdon: Routledge

NUS (2006) UKCOSA international students' survey results Available from: http://www.nusonline.co.uk/campaigns/InternationalStudents/pressreleases/270189.aspx

Oberg, K. (1960) Cultural shock: adjustment to new cultural environments. Practical Anthropology,. 7, 177-82

Okorocha, E. (1996) The international student experience. Journal of Graduate Education, 2, 3, 80-84

O’Reilly, K. (2005) Ethnographic Methods Abingdon, Routledge

Pelletier, C. (2004) The Experiences of International Students in UK Higher Education: a review of unpublished research London, UKCOSA

Persaud, R. (1993) The loneliness of the long-distance student.

Journal of International Education 4, 1, 45-51

Potter, W.J. (1996) An analysis of thinking and research about qualitative methods New Jersey, LEA

Ryan, J. (2005) The student experience In: Carroll, J. and Ryan, J. Teaching international students Abingdon: Routledge

Ryan, J. and Carroll, J. (2005) Canaries in the coalmine: international students in Western universities In: Carroll, J. and Ryan, J. Teaching international students Abingdon: Routledge

Schatzman, L. and Strauss, A. ～(1973) Field research: strategies for a natural sociology New Jersey, Prentice Hall

Scollon, R. and Scollon, S. (1995) Intercultural communication. $\quad$ Massachussets: Blackwell

Sharples, S. (1995) In defence of cultural orientation: a rejoinder to McKinaly and Stephenson. Journal of International Education, 6, 1, 43-52

Smith, A (2006) Improve student experience, Rammell warns The Guardian, March 23

Smith, L. (1987) Discourse across cultures: strategies in world Englishes $\quad$ New York, Prentice Hall

Spradley, J. (1979) The ethnographic interview. New York: Holt, Rinehart and Winston

Storti, C. (1990) The art of crossing cultures. Maine: Intercultural Press

Tarone, E. and Yule, G. (1987) Communication strategies in East-West interactions In: Smith, L. Ed. Discourse across cultures: strategies in world Englishes New York, Prentice Hall 
Taylor, E. (1994) Intercultural competency: a transformative learning process Adult Education Quarterly, 44, 3, 154-174

Taylor, M. (2005) Catch 'em while you can The Guardian, February 8

Taylor, M. (2006) Don't rely on foreign student fees, universities warned The Guardian, March 30

Todd, E. (1997) Supervising overseas students: problem or opportunity? In: McNamara, D. and Harris, R. Eds. Overseas students in HE: issues in teaching and learning London, Routledge

Torbiorn, I. (1994) Dynamics of cross-cultural adaptation In: Althen, G. Ed .Learning across cultures New York, NAFSA

UKCOSA (2004) Broadening our horizons London, UKCOSA

UKCOSA (2006) Student statistics

Available from: http://www.ukcosa.org.uk/student statistics

Ward, C.; Bochner, S.; Furnham, A. ～～(2001) The psychology of culture shock. Hove: Routledge

Ward, C. and Chang, W. 1997 'Cultural fit': a new perspective on personality and sojourner adjustment International Journal of Intercultural Relations, 21, 4, 525-533

Ward, C. and Kennedy, A. (1993) Where's the culture in cross-cultural transition?

Comparative studies of sojourner adjustment Journal of Cross-cultural Psychology, 24, 2, 221-249

Ward, C. and Kennedy, A. (1996) Crossing cultures: the relationship between psychological and sociocultural dimensions of cross-cultural adjustment In J. Pandey, D. Sinha, \& D.P.S. Bhawuk (Eds.), Asian contributions to cross-cultural psychology New Delhi: Sage

Warren, C. and Hackney, J. ～(2000) Gender issues in ethnography, $2^{\text {nd }}$ edition London, Sage 